\title{
Use of IHC and newly designed matriptase inhibitors to elucidate the role of matriptase in pancreatic ductal adenocarcinoma
}

\author{
KERSTIN UHLAND ${ }^{1}$, BENCE SIPHOS ${ }^{2}$, CHRISTOPH ARKONA ${ }^{1}$, MAJ SCHUSTER ${ }^{1}$, \\ BERNHARD PETRI $^{1}$, PETER STEINMETZER ${ }^{1}$, FRIEDEMANN MUELLER ${ }^{1}$, \\ ANDREA SCHWEINITZ ${ }^{1}$, TORSTEN STEINMETZER ${ }^{3}$ and ANDREAS VAN DE LOCHT ${ }^{1}$ \\ ${ }^{1}$ The Medicines Company (Leipzig) GmbH, Deutscher Platz 5, D-04103 Leipzig; ${ }^{2}$ Department of Pathology, \\ University Hospital Schleswig-Holstein, Campus Kiel, Michaelisstrasse 11, D-24105 Kiel; ${ }^{3}$ Department of Pharmacy, \\ Philipps-University of Marburg, Marbacher Weg 6, D-35032 Marburg, Germany
}

Received February 23, 2009; Accepted May 6, 2009

DOI: 10.3892/ijo_00000346

\begin{abstract}
Matriptase, also known as MT-SP1, is a type II transmembrane serine protease strongly implicated in both the development and progression of a variety of epithelial cancers. Evidence comes from studies of its expression in human cancers and from mouse models of spontaneous cancer. Matriptase is considered to be a major activator of two key stimulators of invasive growth, namely hepatocyte growth factor/scatter factor and urokinase-type plasminogen activator. The aim of this study was to examine the role of matriptase in pancreatic ductal adenocarcinoma by expression analysis and functional assays in vitro. Immunohistochemical analysis of matriptase performed on microtissue arrays and large samples of 55 pancreatic ductal adenocarcinomas and on 31 samples of normal pancreatic ducts revealed that although matriptase expression differed greatly in both malignant and normal ductal pancreatic tissue, matriptase scores were significantly $(\mathrm{p}=0.02)$ elevated in pancreatic ductal adenocarcinoma compared to normal pancreatic ducts. To evaluate the role of matriptase during development of pancreatic cancer, we studied the
\end{abstract}

Correspondence to: Dr Andrea Schweinitz, The Medicines Company (Leipzig) GmbH, Deutscher Platz 5d, D-04103 Leipzig, Germany

E-mail: andrea.schweinitz@themedco.com

Abbreviations: As, antisense; AlogP, calculated n-octanol/water partition coefficient; HAI-1, hepatocyte growth factor activator inhibitor 1; HGF/SF, hepatocyte growth factor/scatter factor; HGFR/cMet, HGF receptor/cMet; HRP, horseradish peroxidase; IHC, immunohistochemistry; PDAC, pancreatic ductal adenocarcinoma; PBS, phosphate-buffered saline; RPS 26, ribosomal binding protein 26; s, sense; TMA, tissue microarray; uPA, urokinasetype plasminogen activator; uPAR, uPA receptor

Key words: matriptase, serine protease, immunohistochemistry, protease inhibitors, urokinase, hepatocyte growth factor receptor/ cMet phosphorylation, tumor invasion, pancreatic ductal adenocarcinoma effects of newly designed matriptase inhibitors on the processing of the zymogen of urokinase-type plasminogen activator in the human adenocarcinoma cell lines AsPC-1 and BxPC-3. In both cell lines, at $1 \mu \mathrm{M}$, all matriptase inhibitors completely prevented zymogen activation. At lower inhibitor concentrations, the degree of inhibition of zymogen processing correlated with the affinities of the inhibitors towards matriptase indicating that this is a specific result of matriptase inhibition. Furthermore, matriptase inhibitors reduced the phosphorylation of the HGF receptor/cMet and the overall cellular invasiveness of the human pancreatic adenocarcinoma cell line AsPC-1. Our findings demonstrate for the first time that matriptase may be involved in the progression of pancreatic ductal adenocarcinoma and that matriptase inhibition may contribute to preventing the progression of this devastating disease.

\section{Introduction}

Pancreatic carcinoma is the fifth leading cause of cancer-related death, with an overall five-year survival rate of only 5\%. As pancreatic cancer is one of the most deadly cancers, there is a substantial need for the development of new treatments for affected patients.

One of the major hallmarks of pancreatic cancer is its early systemic dissemination and its extraordinary local tumor progression. According to DiMagno et al (1), these processes are responsible for $\sim 90 \%$ of pancreatic cancer deaths.

It is well established that proteolytic, membrane-associated enzymes expressed on the surface of tumor cells, such as matrix metalloproteinases and proteases of the plasminogen activation cascade, play an important role in tumor growth and progression in general $(2,3)$ and in pancreatic cancer in particular (4,5). In addition, an increasing amount of data suggest an involvement of type II transmembrane serine proteases in tumor growth and progression (6). One of the most prominent members of this class of proteases is matriptase (7), also known as MT-SP1 (8).

The oncogenic potential of matriptase has been most conclusively demonstrated by studies of List et al (9), showing that modest orthotopic overexpression of matriptase in the 
skin of transgenic mice caused spontaneous squamous cell carcinoma and remarkably raised the susceptibility for carcinogen-induced tumors. Concomitant epithelial overexpression of hepatocyte growth factor inhibitor-1 (HAI-1), the cognate inhibitor of matriptase, completely negated the oncogenic effects of matriptase, strongly suggesting that matriptase is a potential anti-tumor target (9).

In development matriptase is thought to mediate its effects by processing the zymogen of prostasin, a serine protease that has been suggested to regulate the epithelial sodium channel EnAC (10), by directly or indirectly processing pro-filaggrin, a major protein involved in keratin aggregation and in terminal epidermal differentiation (11), or both. In contrast, in cancer matriptase is supposed to play diverging roles. Most notably, it is considered to be a key activator of the two principal mediators of invasive growth (12-14), the zymogen form of uPA (pro-uPA) and the single-chain proform of hepatocyte growth factor/scatter factor (pro-HGF/SF) (15-18). Upon activation, uPA binds to its receptor UPAR and triggers matrix degradation through the activation of the plasminogen system, regulates cell adhesion and induces cell migration and proliferation (12). Likewise, processing of pro-HGF/SF leads to the biologically active form, $\mathrm{HGF} / \mathrm{SF}$, that is able to bind to its cell surface receptor cMet and subsequently trigger signal transduction via tyrosine phosphorylation.

Matriptase has been shown to be overexpressed in a wide variety of cancers such as ovarian $(19,20)$, breast $(21,22)$, cervical $(23,24)$ and prostate $(25,26)$ carcinoma. In most cases, high matriptase levels have been correlated with poor clinical outcome $(27,28)$, indicating a functional involvement in oncogenesis.

Matriptase has recently been shown to be proteolytically active in an orthotopic xenograft model of human pancreatic cancer in nude mice (Napp et al, unpublished data). However, to our knowledge, data on matriptase expression in human pancreatic cancer and studies on the functional involvement of matriptase in the progression of pancreatic cancer are not available.

Therefore, in order to elucidate the general role of matriptase in pancreatic cancer, we used immunohistochemistry (IHC) to examine matriptase expression in 55 tissues of human pancreatic ductal adenocarcinoma (PDAC), the predominant form of pancreatic carcinoma (representing $90-95 \%$ of primary pancreatic neoplasms) and in 31 tissues of healthy pancreatic ducts. We showed a small, albeit significant overexpression of matriptase and reasoned that for a protein with a regulatory role at the top of two key activation cascades for invasive growth, minor overexpression might nevertheless result in relevant downstream effects. To test this hypothesis, we used a set of new synthetic matriptase-specific inhibitors to evaluate the role of matriptase as an activator of pro-uPA, of pro-HGF/SF induced HGF receptor/ cMet (HGFR/cMet) signalling and in the overall cellular invasiveness in cell lines of human pancreatic adenocarcinoma. We found that matriptase inhibitors have the potential to eliminate uPA activity in AsPC-1 and BxPC-3 cells completely indicating that cellular pro-uPA activation can be completely abolished by matriptase inhibition. Furthermore, in AsPC-1 cells, matriptase inhibitors resulted in a partial inhibition of pro-HGF/SF-induced
HGFR/cMet phosphorylation and strongly reduced cellular invasiveness.

\section{Materials and methods}

Tissues. Formalin-fixed paraffin-embedded tissues $(5-\mu \mathrm{m})$ were investigated: 45 PDAC on tissue microarray (TMA) (each tumor in duplicate), 10 additional large sections of PDAC and 31 normal pancreatic tissues partly on TMA, partly conventional large sections. The tissues were collected according to the guidelines of the local Ethics Committee.

Immunohistochemistry. IHC analysis was performed by Conbio, Gesellschaft für medizinische Produkte und Dienstleistungen GmbH, Hamburg, Germany, as follows: Heat-mediated antigen retrieval on either TMAs or conventional large tissue sections was carried out in Tris-EDTAcitrate buffer ( $\mathrm{pH} 7.8)$ in a pressure cooker for $3.5 \mathrm{~min}$. Endogenous peroxidase activity was blocked using $3 \% \mathrm{H}_{2} \mathrm{O}_{2}$ solution in methanol followed by blocking with $4 \%$ normal serum (Vectastain-ABC elite kit, Vector Laboratories Inc, CA, USA). Pretreated tissue sections were incubated with the primary antibody rabbit polyclonal anti-matriptase/ST14 (Cterminal epitope; aa 800-855; from Bethyl Laboratories) (Biomol GmbH, Germany) and for control also with another polyclonal antibody, raised against the catalytic domain of matriptase (18) at $5 \mu \mathrm{g} / \mathrm{ml}$ for $45 \mathrm{~min}$ and then with the secondary antibody mouse anti-rabbit from Vectastain-ABC elite kit. The detection was done by avidin-biotin-peroxidase detection with the Vectastain-ABC elite kit according to the manufacturer's instructions.

For specificity control, slides were stained following coincubation of the primary antibody (30 $\mathrm{min}$ ) with the antigen matriptase/ST14 blocking peptide from Bethyl Laboratories (Biomol $\mathrm{GmbH}$ ) at a concentration of $50 \mu \mathrm{g} / \mathrm{ml}$.

All experimental slides were scored for matriptase immunostaining by a histopathologist (B.S.). The evaluation of immunhistochemical stains was performed following an accepted and widely used semi-quantitative scoring system as recommended by Remmele and Stegner (29) (Table I). For comparison of the IHC scores of normal and tumor tissues, the Mann-Whitney test was applied using SPSS 13.0 software.

Cell lines and growth conditions. The human pancreatic adenocarcinoma cell lines AsPC-1 and BxPC-3 were cultured in RPMI-1640 with $10 \%$ foetal calf serum. Cells were purchased from the DSMZ (Braunschweig, Germany), media from Gibco ${ }^{\mathrm{TM}}$ (Invitrogen Corp., Germany). Cells were grown at $37^{\circ} \mathrm{C}$ in $5 \%(\mathrm{v} / \mathrm{v}) \mathrm{CO}_{2}$ in air saturated with $\mathrm{H}_{2} \mathrm{O}$. For the determination of pro-uPA activation, HGFR/cMet phosphorylation and for the invasion assays, cells were washed and serum was replaced by the protease-free serum substitute Ultroser HY (2\%, Ciphergen Biosystems Inc, France) to prevent pro-uPA and pro-HGF/SF processing by serum proteases. All media were supplemented with penicillin (100 U/ml) and streptomycin $(100 \mu \mathrm{g} / \mathrm{ml})$ (Invitrogen).

Real-time PCR. Total RNA isolated from 4x106 cells (RNeasy kit; Qiagen $\mathrm{GmbH}$, Germany) was reversely transcribed using 
Table I. Evaluation system for IHC stains according to Remmele and Stegner (29).

\begin{tabular}{lclccc}
\hline Area & Score & Staining intensity & Score & Result & Valuation \\
\hline 0 & 0 & No staining & 0 & 0 & No expression \\
$<10 \%$ of tumor cells & 2 & Weak staining & 1 & $1-4$ & Weak expression \\
$10-50 \%$ of tumor cells & 3 & Moderate staining & 2 & $5-8$ & Moderate expression \\
$50-80 \%$ of tumor cells & 4 & Strong staining & 3 & $9-12$ & Strong expression \\
$80 \%$ of tumor cells & 5 & - & - & - & - \\
\hline
\end{tabular}

Table II. Primer sequences.

\begin{tabular}{|c|c|c|c|}
\hline Gene & Direction & Sequence & Annealing temperature \\
\hline Matriptase & $\begin{array}{c}\text { s } \\
\text { as }\end{array}$ & $\begin{array}{l}\text { 5'-GTTGTTGGGGGCACGGATGCGGATGAG-3' } \\
\text { 5'-TATACCCCAGTGTTCTCTTTTGATCCA-3' }\end{array}$ & $60^{\circ} \mathrm{C}$ \\
\hline HAI-1 & $\begin{array}{c}\text { S } \\
\text { as }\end{array}$ & $\begin{array}{l}\text { 5'-CCAGACACAGGACTCTGCAA-3' } \\
\text { 5'-ATGGCTACCACCACCACAAT-3' }\end{array}$ & $60^{\circ} \mathrm{C}$ \\
\hline uPA & $\begin{array}{c}\text { s } \\
\text { as }\end{array}$ & $\begin{array}{l}\text { 5'-ACTACTACGGCTCTGAAGTCACCA-3' } \\
\text { 5'-GAAGTGTGAGACTCTCGTGTAGAC-3' }\end{array}$ & $60^{\circ} \mathrm{C}$ \\
\hline uPAR & $\begin{array}{c}\text { s } \\
\text { as }\end{array}$ & $\begin{array}{l}\text { 5'-CCTGGAGCTTGAAAATCTGC-3' } \\
\text { 5'-TGAGGTCACACAGCAAGTCTG-3' }\end{array}$ & $57^{\circ} \mathrm{C}$ \\
\hline $\mathrm{HGF} / \mathrm{SF}$ & $\begin{array}{c}\text { s } \\
\text { as }\end{array}$ & $\begin{array}{l}\text { 5'-TTATGGGGAATGAGAAATGC-3' } \\
\text { 5'-TCGAACAAAAATACCAGGAC-3' }\end{array}$ & $55^{\circ} \mathrm{C}$ \\
\hline HGFR/cMet & $\begin{array}{c}\text { s } \\
\text { as }\end{array}$ & $\begin{array}{l}\text { 5'-CAGACGCCTTGTATGAAGT-3' } \\
\text { 5'-CATAAGTAGCGTTCACATGG-3' }\end{array}$ & $55^{\circ} \mathrm{C}$ \\
\hline Hepsin & $\begin{array}{c}\text { s } \\
\text { as }\end{array}$ & $\begin{array}{l}\text { 5'-CTTCGCTATGATGGAGCACA-3' } \\
\text { 5'-GTCCCGAAAGGGAAGATAGC-3' }\end{array}$ & $57^{\circ} \mathrm{C}$ \\
\hline RPS26 & $\begin{array}{c}\text { S } \\
\text { as }\end{array}$ & $\begin{array}{l}\text { 5'-GCAGCAGTCAGGGACATTTCTG-3' } \\
\text { 5'-TTCACATACAGCTTGGGAAGCA-3' }\end{array}$ & $61^{\circ} \mathrm{C}$ \\
\hline
\end{tabular}

$\mathrm{s}$, sense and as, antisense.

AMV reverse transcriptase and $0.5 \mu \mathrm{g} / \mu \mathrm{l}$ oligo $(\mathrm{dT})_{12-18}$ primer (Invitrogen). First-strand cDNA equivalent to $5 \mathrm{ng}$ RNA was applied in real-time PCR using SYBR-Green JumpStart Taq ReadyMix (Sigma-Aldrich, Germany) and Corbett Rotor-Gene 3000 system (LTF, Germany). The primer sequences are given in Table II.

qPCR conditions were $95^{\circ} \mathrm{C}$ for $3 \mathrm{~min}$, followed by $35-40$ cycles of $95^{\circ} \mathrm{C}$ for $10 \mathrm{sec}$, annealing at optimized temperatures (Table II) for $15 \mathrm{sec}$ and $72^{\circ} \mathrm{C}$ for $18 \mathrm{sec}$ followed by gradual melting from 72 to $96^{\circ} \mathrm{C}$. Fluorescence was recorded after the $72^{\circ} \mathrm{C}$ step. RNA levels were normalized to the housekeeping gene ribosomal binding protein 26 (RPS 26). The experiments were carried out in triplicates and analysed with the Corbett software package.

Matriptase-selective inhibitors. Synthesis, structure-activity relationship and $\mathrm{K}_{\mathrm{i}}$ determinations of the matriptase inhibitors CU-697 and CU-1737 were described previously as inhibitors 44 and 59, respectively (30). The newly designed inhibitors CU-988, CU-990, CU-1804, CU-1807 and CU-1832 were recently described $(31,32)$. For structures, affinities and specificities of the inhibitors see Fig. 1 and Table III, respectively. The specific uPA inhibitor CU-463 (benzylsulfonyl-d-Ser-Ser-4-amidinobenzylamide), used as a control, has been described previously as inhibitor 26 (33) (Table III). All inhibitors were dissolved in $\mathrm{H}_{2} \mathrm{O}$ or $5 \%$ DMSO as $5 \mathrm{mM}$ stock solutions.

Expression and purification of pro-HGF/SF. Recombinant human full-length pro-HGF/SF was expressed and purified, as described previously (34). The pro-HGF/SF-encoding baculovirus was generously provided by Prof. P.M. Comoglio (Institute for Cancer Research and Treatment, Candiolo, Italy).

Measurement of uPA activity and pro-uPA activation. In order to measure uPA activity at the surface of AsPC-1 and BxPC-3 cells, $3 \times 10^{4}$ cells per well were seeded in a 96-well plate in the presence and absence of $0,0.1$, or $1 \mu \mathrm{M}$ of either of the matriptase inhibitors or of the uPA inhibitor CU-463, 
Table III. Inhibition of matriptase and other trypsin-like serine proteases by various inhibitors.

\begin{tabular}{|c|c|c|c|c|c|}
\hline \multirow[b]{2}{*}{ Inhibitor-ID } & \multicolumn{5}{|c|}{$\mathrm{K}_{\mathrm{i}}$ values (nM) } \\
\hline & Matriptase & uPA & Plasmin & Thrombin & $\mathrm{FXa}$ \\
\hline CU-697 & 26.0 & 8200.0 & 3100.0 & 1700.0 & 1300.0 \\
\hline CU-988 & 36.0 & 879.0 & 2560.0 & 2130.0 & 1700.0 \\
\hline CU-990 & 6.1 & 3290.0 & 1330.0 & 1370.0 & 18700.0 \\
\hline CU-1737 & 3.8 & 3600.0 & 2400.0 & 27000.0 & 21000.0 \\
\hline CU-1804 & 2.5 & 6900.0 & 214.0 & 32.9 & 632.0 \\
\hline CU-1807 & 24.5 & 13525.0 & 606.0 & 3.6 & 371.0 \\
\hline CU-1832 & 0.1 & 6.6 & 27.7 & 520.0 & 12.0 \\
\hline CU-463a & 15000.0 & 20.0 & 750.0 & 14000.0 & 13000.0 \\
\hline
\end{tabular}

${ }^{\mathrm{a} u P A}$-specific inhibitor, used as a control.

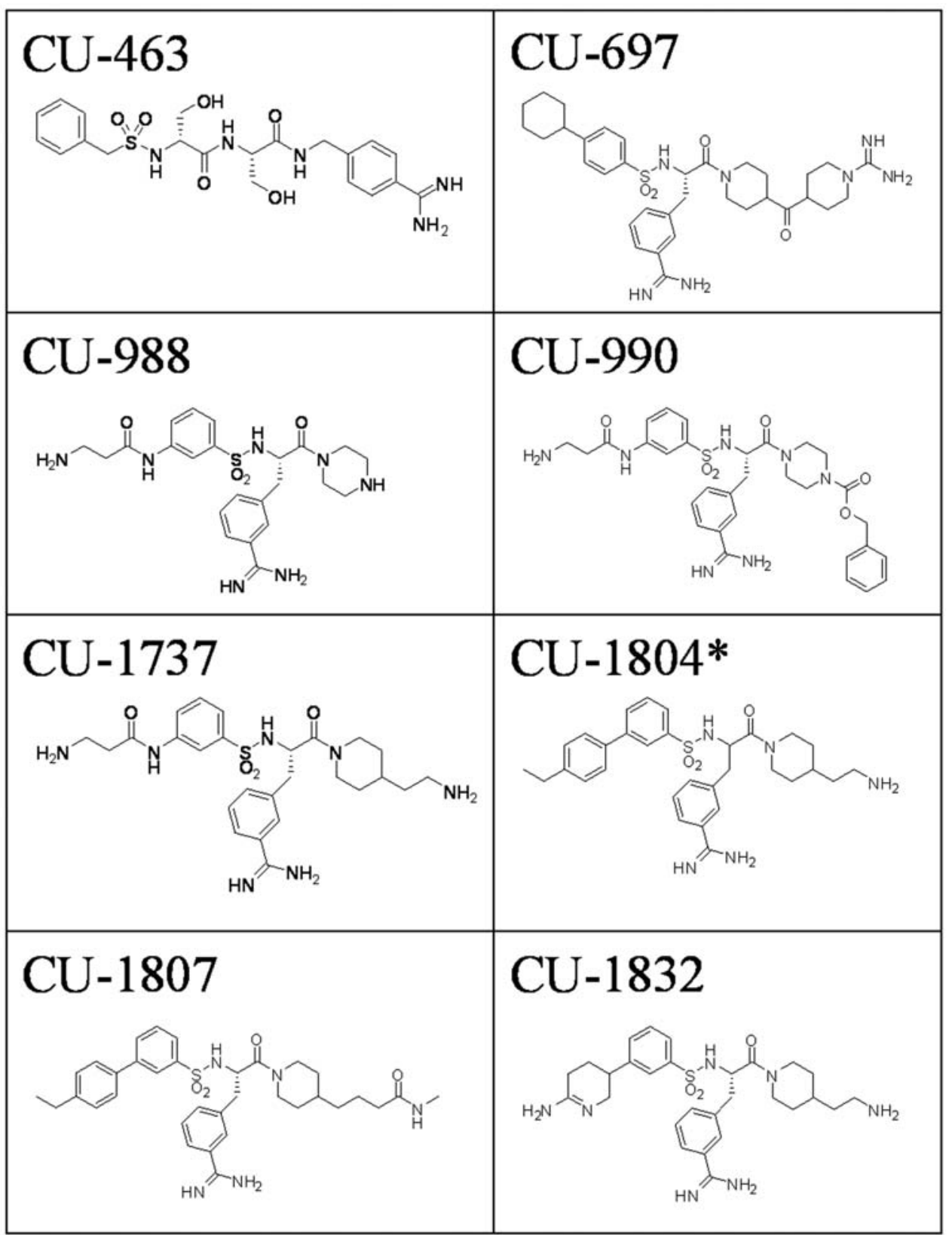

Figure 1. Chemical structures of the inhibitors. "Inhibitor CU-1804 contains racemic 3-amidinophenylalanine. 
respectively. After a $16 \mathrm{~h}$ incubation, $0.3 \mathrm{mM}$ of the chromogenic substrate S-2444 (Chromogenix, Italy) was added and the kinetics of its cleavage were monitored by measuring $\mathrm{OD}_{405}$ over time. Kinetic measurements with human recombinant uPA were performed as reported previously (35). They served as controls for direct inhibition of uPA.

Determination of HGFR/cMet phosphorylation. AsPC-1 cells $\left(10^{6}\right)$ were seeded into $25-\mathrm{cm}^{2}$ polycarbonate culture bottles either in the absence or in the presence of $0.1 \mu \mathrm{M}$ of various matriptase inhibitors. Under these conditions cells remained subconfluent throughout the experiment. After $24 \mathrm{~h}$, phosphorylation of the human HGFR/cMet was stimulated by the addition of $100 \mathrm{ng} / \mathrm{ml}$ recombinant human $\mathrm{pro}-\mathrm{HGF} / \mathrm{SF}$ (final concentration). After $1 \mathrm{~h}$, the medium was removed by aspiration, cell layers were rinsed with phosphate-buffered saline (PBS) and harvested in PBS with a cell scraper. The cells were recovered by centrifugation and the pellets resuspended for $30 \mathrm{~min}$ in ice-cold lysis buffer $(20 \mathrm{mM}$ Tris-HCI pH 8.0, $137 \mathrm{mM} \mathrm{NaCl}, 1 \%)(\mathrm{v} / \mathrm{v})$ Triton X-100 $10 \%$ (v/v) glycerol, 2 mM EDTA, $1 \mathrm{mM} \mathrm{NaF}, 1 \mathrm{mM} \mathrm{Na}-$ orthovanadate, 'Complete' proteinase inhibitors (Roche $\mathrm{GmbH}$, Germany). The lysates were centrifuged for $10 \mathrm{~min}$ at $12,000 \mathrm{x}$ g to remove insoluble debris. Protein concentrations in the supernatants were determined using the bicinchoninic acid (BCA) assay (Pierce, USA) and further diluted to 150 to $200 \mu \mathrm{g} / \mathrm{ml}$.

Phosphorylation of human HGFR/cMet was determined using the human phospho-HGFR/cMet ELISA (R\&D Systems Inc., USA) according to the manufacturer's protocol. Briefly, 15-20 $\mu \mathrm{g}$ protein from AsPC-1 cell extracts were pipetted into an Apogent maxisorb microtiter plate (Nunc, Germany) coated with polyclonal anti-human HGFR/cMet antibody. Antibody-bound HGFR/cMet was probed with a monoclonal anti-phosphotyrosine antibody coupled to horseradish peroxidase (HRP). HRP activity was quantified with the $\mathrm{H}_{2} \mathrm{O}_{2}$ tetramethylbenzidine reaction which gave a direct measure of the extent of HGFR/cMet phosphorylation.

Matrigel invasion assay. Polycarbonate filters ( $8-\mu \mathrm{m}$ pore size) of transwell chambers $(6.5 \mathrm{~mm}$, Costar, Incorporated Corning, NY, USA) were coated with $10 \mu \mathrm{g}$ Matrigel Basement Membrane Matrix (BD Biosciences, Germany). AsPC-1 cells $\left(2 \times 10^{5}\right)$ were seeded in $500 \mu \mathrm{l}$ medium on the Matrigel-coated polycarbonate membrane in the upper compartment and invasive growth was stimulated by the addition of $100 \mathrm{ng} / \mathrm{ml}$ pro-HGF/SF in $500 \mu 1$ medium with or without $20 \mu \mathrm{M}$ inhibitor in the lower compartment. After $48 \mathrm{~h}$, cells that had invaded through the Matrigel and migrated to the lower side of the filter were fixed with methanol and stained with DiffQuick (Dade Behring, Germany) according to the recommendations of the manufacturer. Cells and Matrigel at the upper side of the filter were mechanically removed. Each membrane of the inserts was photographed three times and the images were then quantitatively analyzed with a method that had before been thoroughly evaluated using cell dilution series. In brief, the photographs were transformed to black and white images with Irfan View Software (http://www. irfanview.com) and the black pixel count was then determined with UTHSCSA Image Tool (http://www.uthscsa.edu). The data of the three photographs of one insert were averaged. Means of two independent experiments are given.

\section{Results}

Matriptase is slightly but significantly overexpressed in PDACs compared to normal pancreatic ductal cells. Expression of matriptase in pancreatic ductal adenocarcinoma (PDAC) was evaluated by IHC analyses on TMAs and large-area tissue sections as described above. In total, 55 tissues of PDAC (46 from tumor stage 3, 6 from tumor stage 4, as well as 3 without indicated tumor stage) were compared to 31 samples of normal pancreatic tissue from either disease-free pancreas (12) or peritumoral pancreatic tissues (19).

Matriptase immunostaining resulted in a partly membranebound, partly cytoplasmic reaction. The specificity of the staining reaction was confirmed by competition experiments with the corresponding antigen (Fig. 2E and F). Replacement of the primary antibody 'anti-matriptase/ST14' by another polyclonal antibody raised against the catalytic domain of matriptase yielded comparable results and confirmed the specificity of the staining (data not shown). There were great differences in matriptase scores in both normal and malignant pancreatic ducts (see Fig. 2A-E for representative photographs of IHC analyses). Matriptase expression was mostly weak in normal pancreatic ducts (mean score 1.3, standard deviation 2.1 , range $0-8)$. Ducts in 9 of 31 normal pancreas (29\%) showed weak expression and in two pancreas (6\%) moderately strong expression. All other normal pancreatic tissues expressed no matriptase (65\%). As assessed by the scoring system, matriptase expression was also mostly weak in PDAC (mean score 2.4, standard deviation 2.7, range 0-12). The distribution of matriptase expression in PDACs was as follows: $20(36 \%)$ carcinomas were negative, $25(45 \%)$ carcinomas showed a weak, $8(14.5 \%)$ carcinomas a moderately strong, and $2(3.5 \%)$ PDACs a strong expression (Fig. 2).

Mann-Whitney analysis indicated that matriptase is overexpressed in PDAC compared to normal duct cells $(\mathrm{p}=0.02)$ with median values for the matriptase score of 0 and 2 for normal ductal cells and DACs, respectively (Fig. 3). Thorough analysis of matriptase expression and detailed pathology data yielded no further correlations (data not shown).

The pancreatic adenocarcinoma cell lines AsPC-1 and $B x P C-3$ express relevant factors for downstream signalling by matriptase. In a next step, we tested, whether matriptase might play a functional role in the progression of pancreatic adenocarcinoma in vitro. We chose the human pancreatic adenocarcinoma cell lines AsPC-1 and BxPC-3 for our studies, because matriptase has recently been shown to be proteolytically active in these cell lines in cell culture or in an orthotopic mouse model of pancreatic cancer (Napp et al unpublished data, personal communication). In order to make sure that all relevant factors for the downstream signalling of matriptase were expressed in these cell lines, we studied the expression of the potential matriptase substrates pro-uPA and pro-HGF/SF as well as their receptors $\mathrm{UPAR}$ and HGFR/cMet by qRT-PCR. RNA of Matriptase itself as well as RNAs of pro-uPA, uPAR, pro-HGF/SF and HGFR/cMet were all 


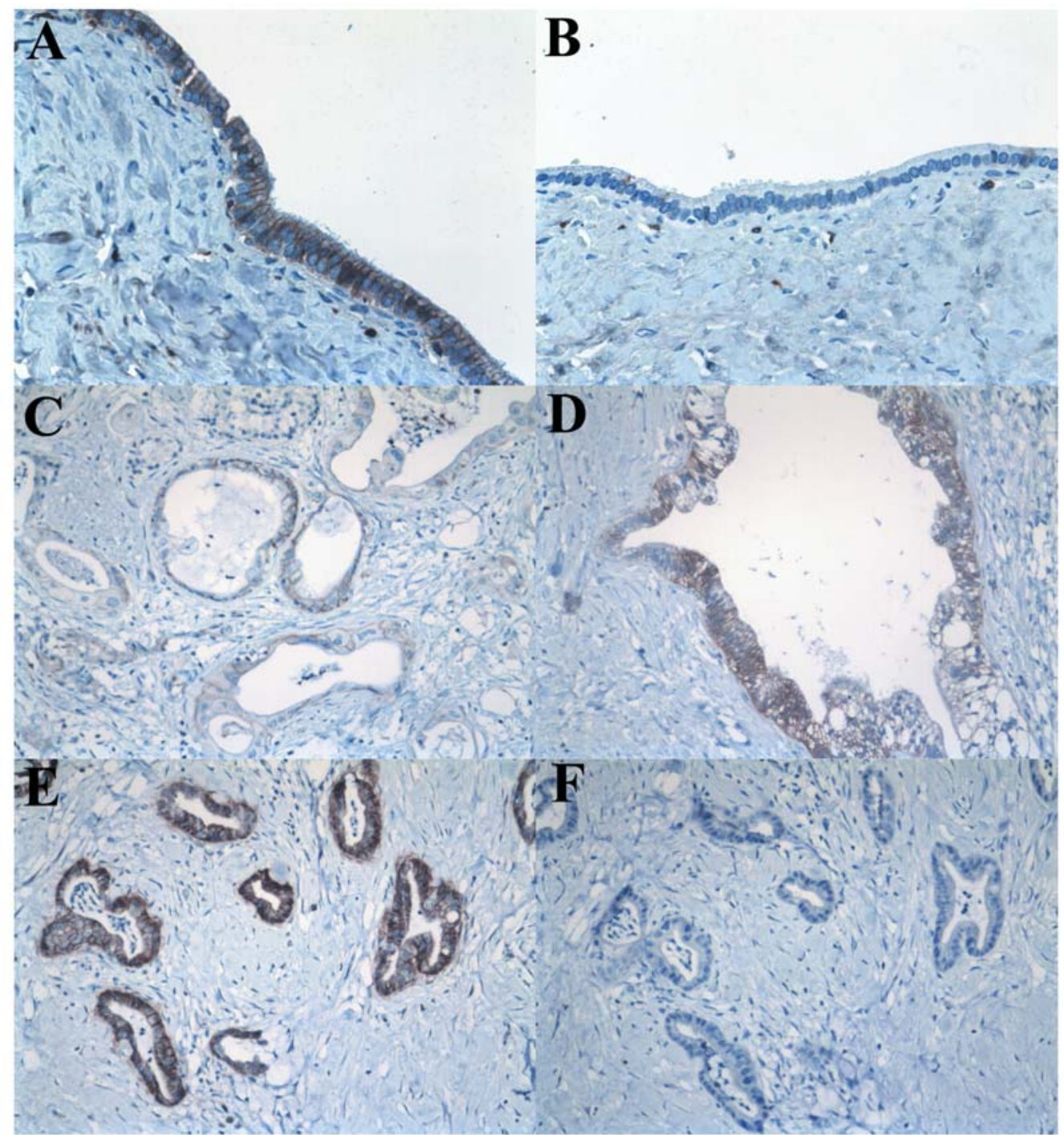

Figure 2. IHC analyses of matriptase expression on tissues of human PDAC and on normal pancreatic duct cells. Matriptase expression differed in normal pancreatic ductal cells (A and B) and in tissues of PDAC (C-E). Examples of IHC results are shown from ductal cells with no matriptase staining (B and C), with weak (A and D) and moderate (E) matriptase staining. The specificity control was done by staining matriptase on matriptase-expressing PDAC in the absence (E) and presence (F) of the corresponding antigen peptide. The administration of antigen to IHC analysis completely abolished staining, indicating that the signal is specific for matriptase (200-fold magnification).

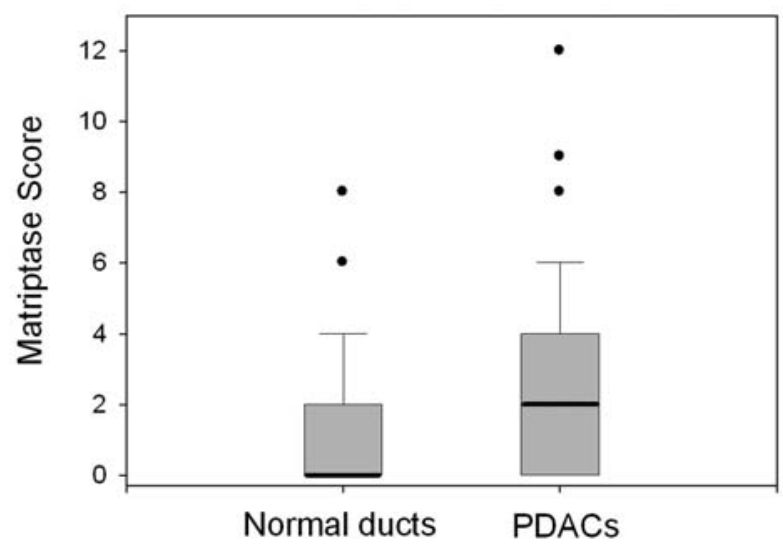

Figure 3. Matriptase score in normal pancreatic ducts and PDACs. Box plot analysis of matriptase scores of normal and malignant pancreatic ducts. The median matriptase scores (black bars) were 0 and 2 for healthy pancreatic ducts and PDAC, respectively. The upper and lower quartiles were 2 and 0 for healthy pancreatic ducts and 4 and 0 for PDAC, respectively. Outliers are shown as circles. present in both cell lines (data not shown). Both cell lines thus met our demands for subsequent analyses. Only low levels of RNA of pro-HGF/SF could be detected. Pro-HGF was therefore given as an external factor where necessary. In addition, we examined the expression of RNA of the cognate matriptase inhibitor HAI-1 and of hepsin, another cancerassociated type II transmembrane serine protease which has also been described to be an efficient activator of pro-HGF/SF $(36,37)$ and pro-uPA $(38)$. Whereas RNA of HAI-1 was present in both cell lines, RNA of hepsin was not detected.

Matriptase-selective inhibitors are able to abolish pro-uPA activation completely in the human pancreatic adenocarcinoma cell lines AsPC-1 and BxPC-3. Matriptase is considered to be one of the most important activators of the urokinase-type plasminogen activation cascade (16-18,39). Therefore, the inhibition of matriptase should result in reduced activation of the zymogen of uPA and thus in reduced uPA activity.

In our matriptase project, inhibitor optimization resulted in a variety of active site serine protease inhibitors with different 
affinities towards matriptase and high selectivity towards other relevant serine proteases. The inhibitors are at least 100 -fold more potent in inhibiting matriptase than in the inhibition of any other serine protease. Exceptions are the inhibitors CU-1804 and CU-1807, which are also potent inhibitors of thrombin (Table III). The chemical structure of the inhibitors is shown in Fig. 1. Synthesis and characterization of the new inhibitors will be described elsewhere [Steinmetzer et al and Schweinitz et al (31,32)]. CU-463 is a uPA-specific inhibitor (33) and was used as a control.

We used this set of inhibitors to assess the role of matriptase on the activation of pro-uPA in pancreatic carcinoma by quantifying the processing of S-2444, a chromogenic substrate that is specific for uPA, in AsPC-1 and BxPC-3 cells. At an inhibitor concentration of $1 \mu \mathrm{M}$, all inhibitors resulted in a $90-100 \%$ reduction of the uPA activity in AsPC-1 and BxPC-3 cells. Since at $1 \mu \mathrm{M}$ the inhibitors are neither cytotoxic, anti-proliferative, nor able to inhibit the proteolytic activity of purified recombinant uPA (data not shown), we conclude that the matriptase-specific inhibitors almost completely prevented the activation of pro-uPA to uPA. As expected, $1 \mu \mathrm{M}$ CU-463, the uPA-specific inhibitor used as control, not only inhibited the uPA activity of the cell lines, but also completely abolished the activity of recombinant uPA (data not shown).

At a lower inhibitor concentration $(0.1 \mu \mathrm{M})$, the inhibitors reduced pro-uPA activation in AsPC- 1 and $\mathrm{BxPC}-3$ cells with differing efficiencies (Fig. 4A). We hypothesized that if matriptase were the key activator of pro-uPA, then, in this experimental setting, the efficiency of the inhibitors in reducing UPA activity should correlate with the affinities of the inhibitors to matriptase.

In fact, we found negative linear correlations of $\mathrm{K}_{\mathrm{i}}$ values and the inhibition of pro-uPA activation in both cell lines. Inhibitors with low $\mathrm{K}_{\mathrm{i}}$ values for matriptase inhibited the uPA activity more efficiently than inhibitors with higher $\mathrm{K}_{\mathrm{i}}$ values for matriptase. The correlation coefficients were -0.8 and -0.66 for AsPC-1 and BxPC-3, respectively. Inhibitor CU-1807 represented a remarkable exception, yielding considerably higher inhibition of pro-uPA activation than predicted from the $\mathrm{K}_{\mathrm{i}}$ value $(24.5 \mathrm{nM})$. Exclusion of this inhibitor improved the correlation coeffcients to -0.93 and -0.91 for AsPC- 1 and BxPC-3, respectively (Fig. 4B and C). We conclude that in AsPC-1 and BxPC-3 cells, the inhibition of pro-uPA activation is achieved by specifically inhibiting matriptase and not by inhibition of any other serine protease.

Effects of matriptase inhibitors on pro-HGF/SF-induced cMet phosphorylation in the human pancreatic adenocarcinoma cell line AsPC-1. In addition to pro-uPA, matriptase is known to process pro-HGF/SF efficiently $(15,18,39)$. Therefore, inhibition of matriptase should result in reduced activation of pro-HGF/ $\mathrm{SF}$ and thus in reduced tyrosine phosphorylation of HGFR/cMet.

We assessed the efficacy of various matriptase-selective inhibitors on the inhibition of pro-HGF/SF-induced cMet signaling by measuring their effects on the pro-HGF/SFinduced tyrosine phosphorylation of HGFR/cMet in the human pancreatic cell line AsPC-1. HGFR/cMet tyrosine phosphorylation was determined with a cMet phosphorylation ELISA as described in Materials and methods.
A

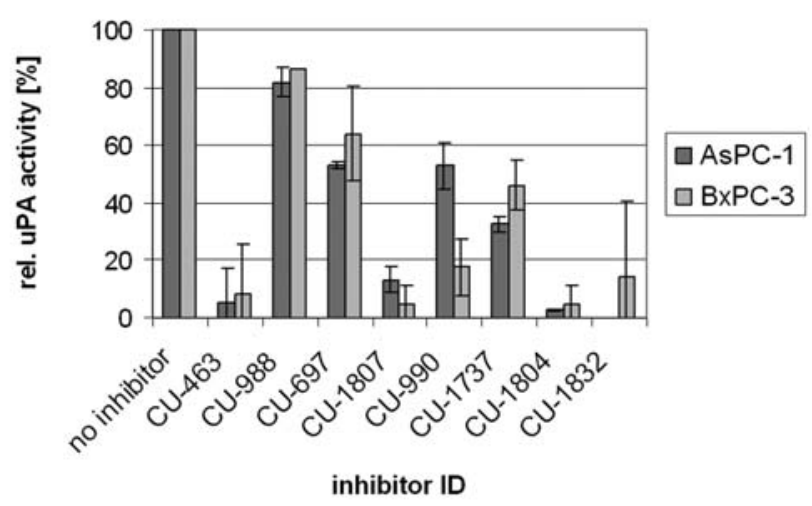

B

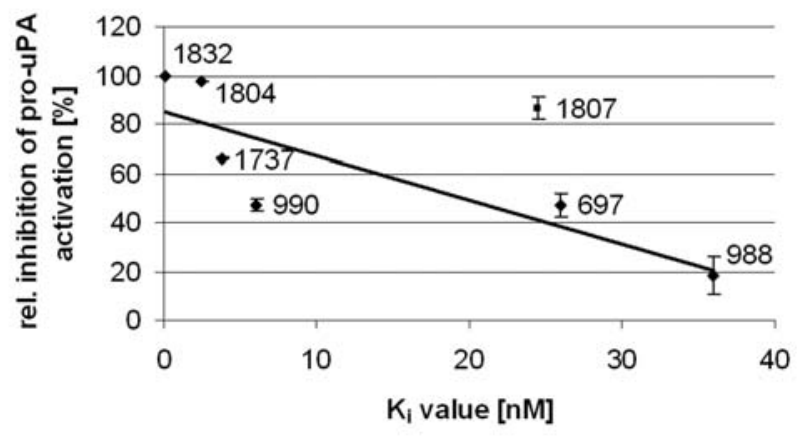

C

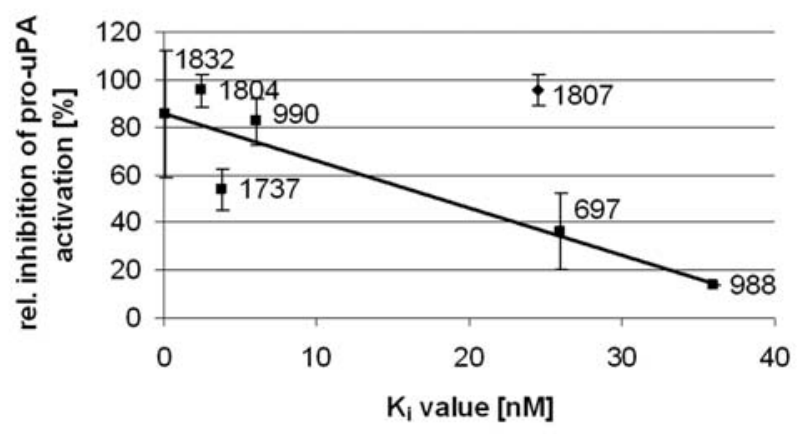

Figure 4. Inhibition of S-2444 cleavage by matriptase-selective serine protease inhibitors in the human pancreas carcinoma cell lines AsPC-1 and BxPC-3 (A). The human pancreas cell lines AsPC-1 and BxPC-3 were incubated with $0.3 \mathrm{mM}$ of the chromogenic uPA-specific substrate S-2444 in the absence or presence of $0.1 \mu \mathrm{M}$ of various matriptase-selective inhibitors as described in Materials and methods. The uPA-specific inhibitor CU-463 was used as positive control. Substrate cleavage was detected as changes of $\mathrm{OD}_{405}$ per time. Activities of non-inhibited samples were taken as $100 \%$ active and served as references. The matriptase inhibitors are listed with increasing affinities (decreasing $\mathrm{K}_{\mathrm{i}}$ values) from the left to the right. As the matriptaseselective inhibitors were neither toxic nor anti-proliferative and did not inhibit the proteolytic activity of uPA, the data allow the measurement of the activation of pro-uPA at the cell surface. The data are means of two independent experiments performed as duplicates. The bars indicate standard deviations. Correlation of $\mathrm{K}_{\mathrm{i}}$ values for matriptase with the efficacy of inhibitors to prevent pro-uPA activation in the human pancreatic carcinoma cell line AsPC-1 (B) and BxPC-3 (C). To test for correlation of the inhibitors efficacy of matriptase inhibition and their capability in inhibiting the cleavage of the zymogen pro-uPA, the capability of $0.1 \mu \mathrm{M}$ of various matriptasespecific inhibitors to prevent the activation of pro-uPA in the human cell lines of pancreatic carcinoma (data from A) was plotted against their $\mathrm{K}_{\mathrm{i}}$ values for matriptase. Inhibitor CU-1807 was treated as an exception and was excluded from the trend line. The numbers in the graphs are short forms of the inhibitor IDs, which are typically named as e.g. CU-1737. 


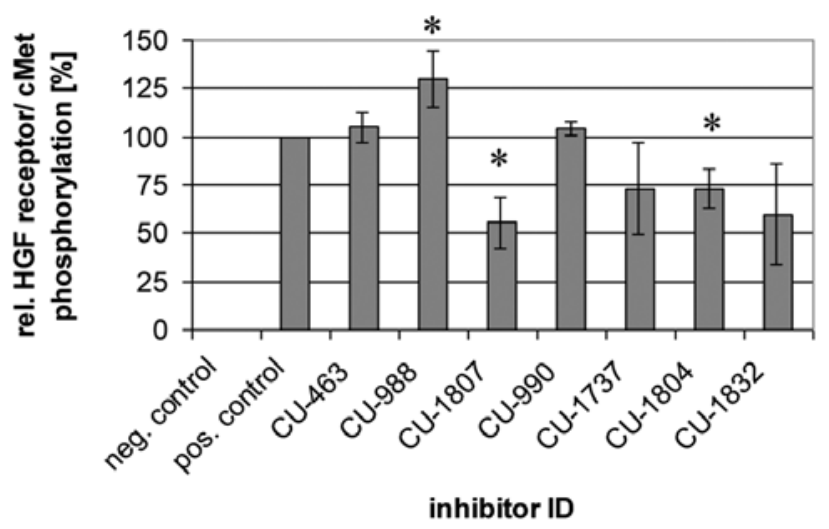

Figure 5. Effects of various matriptase inhibitors on the HGFR/cMet tyrosine phosphorylation in the human pancreatic adenocarcinoma cell line AsPC-1. The human pancreatic cell line AsPC-1 was stimulated by administration of $100 \mathrm{ng} / \mathrm{ml}$ recombinant pro-HGF/SF in the absence or presence of $0.1 \mu \mathrm{M}$ of various matriptase-selective inhibitors. After $1 \mathrm{~h}, \mathrm{HGFR} / \mathrm{cMet}$ phosphorylation was determined with a HGFR/cMet phosphorylation ELISA. Samples without pro-HGF/SF administration measured the basal level of HGFR/cMet phosphorylation and served as negative control. Basal levels were substracted from all measurements. Samples with pro-HGF/SF stimulation without inhibitor were the positive control and defined as $100 \% \mathrm{HGFR} / \mathrm{cMet}$ phosphorylation. The graph shows mean values of three independent experiments performed as triplicates with standard deviations. Significant results $(\mathrm{p}<0.05)$ are marked with an asterix.

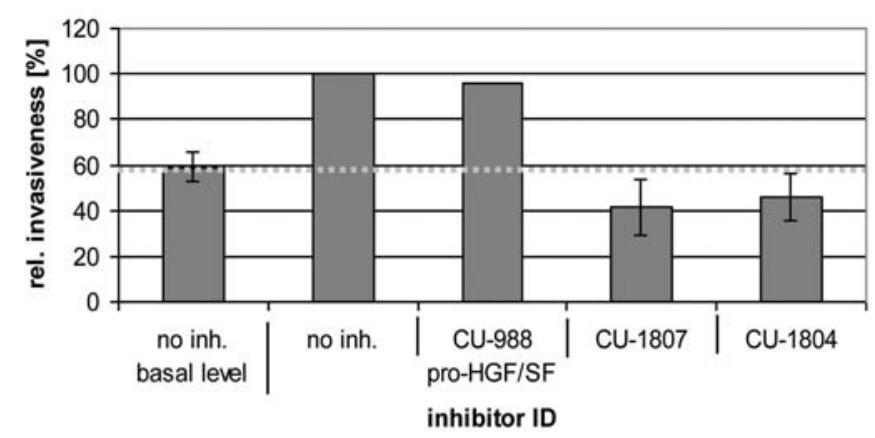

Figure 6. Effects of various matriptase inhibitors on the invasiveness of AsPC-1 cells. Invasion of the human pancreatic AsPC-1 cells through reconstituted extracellular matrix (Matrigel) was stimulated by the administration of $100 \mathrm{ng} / \mathrm{ml}$ recombinant $\mathrm{pro}-\mathrm{HGF} / \mathrm{SF}$ in the absence or presence of $10 \mu \mathrm{M}$ matriptase inhibitors CU-988, CU-1804 and CU-1807 in the lower compartment. After $48 \mathrm{~h}$, the cells of the upper compartment were removed and the cells of the lower compartment were fixed and stained for analysis. Samples without pro-HGF/SF administration measured the basal level of cellular invasiveness (gray dotted line). Samples with pro-HGF/SF stimulation without inhibitor were the positive control and defined as $100 \%$ invasiveness. The graph shows mean values of two independent experiments performed as duplicates.

Consistent with the detection of pro-HGF/SF mRNA (see above), analysis of non-stimulated AsPC-1 cells showed a basal level of HGFR/cMet phosphorylation, indicating the presence of receptor ligand in this cell line. Nevertheless, to give a new and well-defined stimulus of $\mathrm{HGFR} / \mathrm{cMet}$ phosphorylation, $100 \mathrm{ng} / \mathrm{ml}$ recombinant pro-HGF/SF was administered to the cells, resulting in a 2-2.5-fold increase of
HGFR/cMet phosphorylation after $1 \mathrm{~h}$. At a final inhibitor concentration of $0.1 \mu \mathrm{M}$ the serine protease inhibitors with the highest affinities towards matriptase (CU-1737, CU-1804 and CU-1832) had the most pronounced effects on proHGF/ SF-induced HGFR/cMet phosphorylation. They reduced proHGF/SF-induced tyrosine phosphorylation by $\sim 30 \%$ (Fig. 5). However, of these, only the inhibition obtained with CU-1804 was statistically significant, a finding that might in part be explained by the high standard deviations in this assay. In addition, CU-1807, albeit it has a significantly lower affinity towards matriptase $\left(\mathrm{K}_{\mathrm{i}}=24.5 \mathrm{nM}\right)$, also strongly and significantly reduced HGFR/cMet phosphorylation. This inhibitor had already been identified in the pro-uPA activation assay as a compound the efficiency of which was more pronounced than that deduced from the affinity towards matriptase (see above). In contrast, CU-990 had no effect and CU-988, for reasons unknown, even stimulated HGFR/cMet phosphorylation.

We conclude that in AsPC-1 cells, matriptase inhibition may result in a partial inhibition of HGFR/cMet phosphorylation.

Matriptase inhibitors strongly reduce invasiveness of AsPC-1 cells in a Matrigel invasion assay. As shown above, matriptase inhibition resulted in complete inhibition of prouPA processing and in up to $40 \%$ reduction in $\mathrm{HGFR} / \mathrm{cMet}$ phosphorylation. As both active uPA and phosphorylated HGFR/cMet are well known to trigger invasive growth, in a next step, we investigated whether the effects of the inhibitors would manifest in reduced cellular invasiveness. To do so, we selected those inhibitors that yielded a significant effect on the pro-HGF/SF-induced cMet phosphorylation, namely CU-988, CU-1804, and CU-1807, to study their effects on the invasiveness of AsPC-1 cells in a Matrigel invasion assay.

Non-stimulated AsPC-1 cells represented the basal level of invasiveness. Administration of $100 \mathrm{ng} / \mathrm{ml} \mathrm{pro}-\mathrm{HGF} / \mathrm{SF}$ stimulated the invasiveness $\sim 1.7$-fold (Fig. 6). The final inhibitor concentrations in the assay were 1 and $10 \mu \mathrm{M}$, respectively. At $1 \mu \mathrm{M}$, none of the three inhibitors showed any effects in cellular invasiveness (data not shown). However, at $10 \mu \mathrm{M}$, the matriptase inhibitors CU-1804 and CU-1807, i.e. those which significantly reduced pro$\mathrm{HGF} / \mathrm{SF}$-induced HGFR/cMet phosphorylation, reduced the relative cellular invasiveness of pro-HGF/SF-stimulated AsPC-1 cells $>2$-fold (Fig. 6). Since at this concentration the inhibitors are neither cytotoxic nor anti-proliferative (data not shown), we conclude that these inhibitors were able to counteract the pro-invasive effect of pro-HGF/SF completely and in addition to reduce invasiveness below the basal level by $\sim 25 \%$ (Fig. 6). The matriptase inhibitors thus have the potential to reduce invasive growth of the pancreatic carcinoma cell line AsPC-1 substantially, probably by simultaneously inhibiting HGFR/cMet phosphorylation and pro-uPA activation.

Inhibitor CU-988, which induced the HGFR/cMet phosphorylation, had almost no effect on cellular invasiveness. Here, the pro-invasive effects of the induced cMet phosphorylation may have abrogated the anti-invasive effects of the inhibition of pro-uPA activation. 


\section{Discussion}

Overexpression of matriptase has been demonstrated in a variety of tumors. The finding that matriptase expression correlated with tumor stage, clinical outcome or both in pancreatic, breast, ovarian, and cervical carcinoma, suggested that this protease is a biomarker for these carcinomas and at the same time implicated a functional role of matriptase in tumor progression $(27,28)$. To our knowledge, data on the expression and role of matriptase in PDAC are not yet published. To investigate the expression of matriptase in PDAC, we performed IHC analysis on TMAs and large sections of PDAC (55) and tissues of healthy pancreatic ducts (33). We show that a wide range of matriptase expression levels, ranging from no to high expression, can be found in both healthy ducts and PDAC.

Consistent with the results of IHC analyses on normal pancreatic tissue (40), we found no or only very weak immunoreactivity of islet cells and acinar secretory cells. However, non-concordantly, Oberst et al (40) showed very strong matriptase staining of pancreatic ducts, whereas in our study pancreatic ducts mostly showed either no or only weak matriptase staining. Stronger matriptase stainings were exceptions, so possibly, the section shown by Oberst et al coincidentially represented such an exception.

Mann-Whitney analysis of our IHC data revealed that matriptase is significantly overexpressed in PDAC compared to healthy pancreatic ducts $(\mathrm{p}=0.02)$ with median matriptase scores of 0 and 2 for healthy pancreatic ducts and PDAC, respectively. However, since all matriptase scores, from no expression to high expression were detected in both healthy and malignant tissues, we would not propose matriptase to be a diagnostic or prognostic tool in PDAC.

As the matriptase: HAI-1 ratio has been shown to correlate with clinical outcome or tumor stage for ovarian and prostate carcinoma, respectively $(26,41)$, it will be also interesting to study the ratio of matriptase to HAI-1 in PDAC.

Within our scoring system, ranging from 0 to 12 (29), the median matriptase score of 2 is relatively low. Nevertheless, having in mind the results of List et al (9) showing that matriptase expressed in the skin of mice at a total level 1.21.4-fold of normal led to spontaneous development of squamous cell carcinoma in early midlife and also to increase susceptibility to chemically-induced carcinogenesis dramatically, a slight degree of overexpression might very well be of functional relevance. This is all the more relevant, since matriptase was recently shown to be proteolytically active in an orthotopic mouse model of human pancreatic cancer (Napp et al, unpublished data), a remarkable finding for a protease the regulation of which is known to be very intricate $(42,43)$.

To study the role of matriptase in pancreatic adenocarcinoma in vitro, we used a new set of well-characterized serine protease inhibitors with high affinity and selectivity to matriptase [Steinmetzer et al and Schweinitz et al $(31,32)$ ] and two cell lines, AsPC-1 and BxPC-3, which were known to express proteolytically active matriptase in vitro (Napp et al, unpublished data). We showed that matriptase inhibitors are able to abolish pro-uPA activation at the surface of these cells completely. At $1 \mu \mathrm{M}$, all inhibitors reduced the cleavage of S-2444, an uPA-specific chromogenic substrate, by at least $90 \%$. Since at this concentration the inhibitors neither affect the viability, the proliferation rates, nor inhibit recombinant active uPA, we conclude that they act by inhibiting pro-uPA zymogen activation. Our observation that at $0.1 \mu \mathrm{M}$ the efficacy of the inhibitors to suppress pro-uPA activation correlates with their inhibitory potency in enzyme kinetic assays strongly suggests that this effect is specific for matriptase inhibition. In AsPC-1 and BxPC-3 cells, matriptase thus seems to be the sole activator of pro-uPA. mRNA of Hepsin, another efficient activator of pro-uPA (38) is neither expressed in AsPC-1 nor in BxPC-3 cells.

The involvement of matriptase in pro-uPA activation has recently been shown for cell lines of human prostate adenocarcinoma (PC-3) (18), ovarian cancer (HRA) (16), and for the monocytic cell line THP-1 (17), but has not yet been demonstrated for pancreatic adenocarcinoma.

In this tumor type, the importance of the uPA system for tumor progression was demonstrated by studies of expression and function. In Northern blot analysis, mRNA levels of uPA and its receptor UPAR were shown to be increased 6- and 4-fold, respectively, when compared to normal specimens. Correlation of these data with clinical outcome demonstrated significantly decreased survival among patients who overexpressed both UPA and UPAR (median 9 months) compared to patients who had no overexpression of these factors, or overexpression of only one of these factors (median 18 months) (44).

In a mouse model of human pancreatic carcinoma using L3.6pl cells, inhibition of uPA signalling with an anti-uPAR monoclonal antibody reduces orthotopic growth, local invasion, and liver metastasis by 75,100 and $53 \%$, respectively (45).

In AsPC-1 cells, at concentrations of $0.1 \mu \mathrm{M}$, those matriptase inhibitors that performed best in the pro-uPA activation assay were also the most effective in the HGFR/ cMet phosphorylation assay. We refrained from studying these effects in BxPC-3 cells, since it was shown recently that these cells do not or only weakly respond with increased migration and invasiveness to $\mathrm{HGF} / \mathrm{SF}$ stimulation $(46,47)$. The inhibitors achieved $\sim 30 \%$ inhibition of pro-HGF/SFinduced HGFR/cMet phosphorylation. This result suggests that in this experimental setting, in addition to matriptase, other proteases might be involved in pro-HGF/SF activation and subsequent HGFR/cMet phosphorylation. Since the uPAspecific inhibitor CU-463 was not effective in this assay and no uPA activity was found in the presence of some of the matriptase inhibitors at $0.1 \mu \mathrm{M}$, uPA can be excluded as a potential activator for pro-HGF/SF (34). Hepsin, another potential activator of pro-HGF/SF $(36,37)$, is not expressed in AsPC-1 cells. One could argue that due to 'interconnecting proteolytic systems, cascades and circuits' (48), matriptase inhibition might stimulate the expression of hepsin. However, as in the concentration range applied in the assay, none of the inhibitors showed any inhibitory effect on recombinant hepsin (data not shown), even if hepsin would be upregulated, it need not be considered.

The importance of the HGF/cMet system in pancreatic cancer has been shown with the small molecule cMet inhibitor PHA-665752 (47) and with the HGF antagonist NK4 (recently 
reviewed in ref. 49). NK4 expression reduced HGF-induced migration of AsPC-1 cells to the level of non-stimulated cells (50).

$\mathrm{HGF} / \mathrm{SF}$ is known to induce the expression of uPA and uPAR (45). Therefore, the effects of HGF/SF and uPA on invasiveness are interconnected. For example, uPA inhibition by either amiloride or an UPAR antibody significantly reduced the HGF/SF-induced invasiveness of the pancreatic cell line L3.6pl (45). The matriptase inhibitors CU-1804 and CU-1807 reduced the invasiveness of pro-HGF/SF-induced AsPC-1 cells to a level below that of non-stimulated cells. However, compared to the other assays, here, the inhibitors were only effective at higher concentrations. This may be explained by a reduced availability of the inhibitors in the presence of Matrigel.

Inhibitor CU-1807 performed better than expected from its $\mathrm{K}_{\mathrm{i}}$ value and thereby represented an interesting exception. As this inhibitor is more lipophilic (partition coefficient $\mathrm{A} \log \mathrm{P}=3.59)$ than all other inhibitors tested $(\mathrm{A} \log \mathrm{Ps}<2$, AlogPs were calculated using the SAR Navigator ${ }^{\mathrm{TM}}$, version 1.5, Tripos Inc.), we speculated that this inhibitor might penetrate the cell membrane and act intracellularly on a relevant and structurally similar serine protease with unknown identity. Effects that result form the inhibition of another structurally similar extracellular serine protease, such as matriptase-2 (51) or another type II transmembrane serine protease (6), can also not be completely excluded.

In summary, we conclude that in a subgroup of PDAC, matriptase may contribute to tumor progression and that matriptase inhibitors may have the potential to counteract the invasive potential of pancreatic carcinoma cells.

\section{Acknowledgements}

We thank Gudrun Heide and Henriette Undeutsch for experimental assistance. This study was supported by the 'Technologieförderung' with funds of the European Regional Development Fund (ERDF) and with funds of the Free State of Saxony.

\section{References}

1. DiMagno EP, Reber HA and Tempero MA: AGA technical review on the epidemiology, diagnosis, and treatment of pancreatic ductal adenocarcinoma. American Gastroenterological Association. Gastroenterology 117: 1464-1484, 1999.

2. Duffy MJ, McGowan PM and Gallagher WM: Cancer invasion and metastasis: changing views. J Pathol 214: 283-293, 2008.

3. Fingleton B: Matrix metalloproteinases: roles in cancer and metastasis. Front Biosci 11: 479-491, 2006.

4. Patten LC and Berger DH: Role of proteases in pancreatic carcinoma. World J Surg 29: 258-263, 2005.

5. Keleg S, Buchler P, Ludwig R, Buchler MW and Friess H: Invasion and metastasis in pancreatic cancer. Mol Cancer 2: $14-19,2003$

6. Szabo R and Bugge TH: Type II transmembrane serine proteases in development and disease. Int J Biochem Cell Biol 40 1297-1316, 2008.

7. Lin CY, Anders J, Johnson M, Sang QA and Dickson RB: Molecular cloning of cDNA for matriptase, a matrix-degrading serine protease with trypsin-like activity. J Biol Chem 274: 18231-18236, 1999.

8. Takeuchi T, Shuman MA and Craik CS: Reverse biochemistry: use of macromolecular protease inhibitors to dissect complex biological processes and identify a membrane-type serine protease in epithelial cancer and normal tissue. Proc Natl Acad Sci USA 96: 11054-11061, 1999.
9. List K, Szabo R, Molinolo A, Sriuranpong V, Redeye V, Murdock T, Burke B, Nielsen BS, Gutkind JS and Bugge TH: Deregulated matriptase causes ras-independent multistage carcinogenesis and promotes ras-mediated malignant transformation. Genes Dev 19: 1934-1950, 2005.

10. Netzel-Arnett S, Currie BM, Szabo R, Lin CY, Chen LM, Chai KX, Antalis TM, Bugge TH and List K: Evidence for a matriptase-prostasin proteolytic cascade regulating terminal epidermal differentiation. J Biol Chem 281: 32941-32945, 2006.

11. List K, Szabo R, Wertz PW, Segre J, Haudenschild CC, Kim SY and Bugge TH: Loss of proteolytically processed filaggrin caused by epidermal deletion of Matriptase/MT-SP1. J Cell Biol 163: 901-910, 2003.

12. Dano K, Behrendt N, Hoyer-Hansen G, Johnsen M, Lund LR, Ploug $\mathrm{M}$ and Romer J: Plasminogen activation and cancer. Thromb Haemost 93: 676-681, 2005.

13. Benvenuti S and Comoglio PM: The MET receptor tyrosine kinase in invasion and metastasis. J Cell Physiol 213: 316-325, 2007.

14. Peruzzi B and Bottaro DP: Targeting the c-Met signaling pathway in cancer. Clin Cancer Res 12: 3657-3660, 2006.

15. Lee SL, Dickson RB and Lin CY: Activation of hepatocyte growth factor and urokinase/plasminogen activator by matriptase, an epithelial membrane serine protease. J Biol Chem 275: 36720-36725, 2000.

16. Suzuki M, Kobayashi H, Kanayama N, Saga Y, Suzuki M, Lin CY, Dickson RB and Terao T: Inhibition of tumor invasion by genomic down-regulation of matriptase through suppression of activation of receptor-bound pro-urokinase. J Biol Chem 279: 14899-14908, 2004.

17. Kilpatrick LM, Harris RL, Owen KA, Bass R, Ghorayeb C, Bar-Or A and Ellis V: Initiation of plasminogen activation on the surface of monocytes expressing the type II transmembrane serine protease matriptase. Blood 108: 2616-2623, 2006.

18. Foerbs D, Thiel S, Stella MC, Stuerzebecher A, Schweinitz A, Steinmetzer T, Stuerzebecher J and Uhland K: In vitro inhibition of matriptase prevents invasive growth of cell lines of prostate and colon carcinoma. Int J Oncol 27: 1061-1070, 2005.

19. Jin JS, Hsieh DS, Loh SH, Chen A, Yao CW and Yen CY: Increasing expression of serine protease matriptase in ovarian tumors: tissue microarray analysis of immunostaining score with clinicopathological parameters. Mod Pathol 19: 447-452, 2006.

20. Tanimoto H, Shigemasa K, Tian X, Gu L, Beard JB, Sawasaki T and O'Brien TJ: Transmembrane serine protease TADG-15 (ST14/Matriptase/MT-SP1): expression and prognostic value in ovarian cancer. Br J Cancer 92: 278-283, 2005.

21. Jin JS, Cheng TF, Tsai WC, Sheu LF, Chiang H and Yu CP: Expression of the serine protease, matriptase, in breast ductal carcinoma of Chinese women: correlation with clinicopathological parameters. Histol Histopathol 22: 305-309, 2007.

22. Kang JY, Dolled-Filhart M, Ocal IT, Singh B, Lin CY, Dickson RB, Rimm DL and Camp RL: Tissue microarray analysis of hepatocyte growth factor/Met pathway components reveals a role for Met, matriptase, and hepatocyte growth factor activator inhibitor 1 in the progression of node-negative breast cancer. Cancer Res 63: 1101-1105, 2003.

23. Lee JW, Yong SS, Choi JJ, Lee SJ, Kim BG, Park CS, Lee JH, Lin CY, Dickson RB and Bae DS: Increased expression of matriptase is associated with histopathologic grades of cervical neoplasia. Hum Pathol 36: 626-633, 2005.

24. Santin AD, Cane S, Bellone S, Bignotti E, Palmieri M, De Las Casas LE, Anfossi S, Roman JJ, O'Brien T and Pecorelli S: The novel serine protease tumor-associated differentially expressed gene-15 (matriptase/MT-SP1) is highly overexpressed in cervical carcinoma. Cancer 98: 1898-1904, 2003.

25. Riddick AC, Shukla CJ, Pennington CJ, Bass R, Nuttall RK, Hogan A, Sethia KK, Ellis V, Collins AT, Maitland NJ, Ball RY and Edwards DR: Identification of degradome components associated with prostate cancer progression by expression analysis of human prostatic tissues. Br J Cancer 92: 2171-2180, 2005.

26. Saleem M, Adhami VM, Zhong W, Longley BJ, Lin CY, Dickson RB, Reagan-Shaw S, Jarrard DF and Mukhtar H: A novel biomarker for staging human prostate adenocarcinoma: overexpression of matriptase with concomitant loss of its inhibitor, hepatocyte growth factor activator inhibitor-1. Cancer Epidemiol Biomarkers Prev 15: 217-227, 2006.

27. Uhland K: Matriptase and its putative role in cancer. Cell Mol Life Sci 63: 2968-2978, 2006.

28. List K, Bugge TH and Szabo R: Matriptase: potent proteolysis on the cell surface. Mol Med 12: 1-7, 2006 
29. Remmele W and Stegner HE: Recommendation for uniform definition of an immunoreactive score (IRS) for immunohistochemical estrogen receptor detection (ER-ICA) in breast cancer tissue. Pathologe 8: 138-140, 1987.

30. Steinmetzer T, Schweinitz A, Stuerzebecher A, Doennecke D, Uhland K, Schuster O, Friedrich R, Than ME, Bode W and Stuerzebecher J: Secondary amides of sulfonylated 3-aminophenylalanine - New potent and selective inhibitors of matriptase. J Med Chem 49: 4116-4126, 2006.

31. Steinmetzer T, Dönnecke D, Korsonewski M, Neuwirth C, Steinmetzer P, Schulze A, Saupe SM and Schweinitz A: Modification of the N-terminal sulfonyl residue in 3-amidinophenylalanine-based matriptase inhibitors. Bioorg Med Chem Lett 19: 67-73, 2009.

32. Schweinitz A, Dönnecke D, Ludwig A, Steinmetzer P, Schulze A, Kotthaus J, Wein S, Clement B and Steinmetzer T: Incorporation of neutral C-terminal residues in 3-amidinophenylalaninederived matriptase inhibitors. Bioorg Med Chem Lett 19: 1960-1965, 2009.

33. Schweinitz A, Steinmetzer T, Banke IJ, Arlt MJ, Stuerzebecher A, Schuster O, Geissler A, Giersiefen H, Zeslawska E, Jacob U, Kruger A and Stuerzebecher J: Design of novel and selective inhibitors of urokinase-type plasminogen activator with improved pharmacokinetic properties for use as antimetastatic agents. J Biol Chem 279: 33613-33622, 2004.

34. Naldini L, Vigna E, Bardelli A, Follenzi A, Galimi F and Comoglio PM: Biological activation of pro-HGF (hepatocyte growth factor) by urokinase is controlled by a stoichiometric reaction. J Biol Chem 270: 603-611, 1995.

35. Stuerzebecher J, Prasa D, Hauptmann J, Vieweg H and Wikstrom P: Synthesis and structure-activity relationships of potent thrombin inhibitors: piperazides of 3-amidinophenylalanine. J Med Chem 40: 3091-3099, 1997.

36. Kirchhofer D, Peek M, Lipari MT, Billeci K, Fan B and Moran P Hepsin activates pro-hepatocyte growth factor and is inhibited by hepatocyte growth factor activator inhibitor-1B (HAI-1B) and HAI-2. FEBS Lett 579: 1945-1950, 2005.

37. Herter S, Piper DE, Aaron W, Gabriele T, Cutler G, Cao P, Bhatt AS, Choe Y, Craik CS, Walker N, Meininger D, Hoey T and Austin RJ: Hepatocyte growth factor is a preferred in vitro substrate for human hepsin, a membrane-anchored serine protease implicated in prostate and ovarian cancers. Biochem J 390: 125-136, 2005.

38. Moran P, Li W, Fan B, Vij R, Eigenbrot C and Kirchhofer D: Pro-urokinase-type plasminogen activator is a substrate for hepsin. J Biol Chem 281: 30439-30446, 2006.

39. Takeuchi T, Harris JL, Huang W, Yan KW, Coughlin SR and Craik CS: Cellular localization of membrane-type serine protease 1 and identification of protease-activated receptor-2 and single-chain urokinase-type plasminogen activator as substrates. J Biol Chem 275: 26333-26342, 2000.
40. Oberst MD, Singh B, Ozdemirli M, Dickson RB, Johnson MD and Lin CY: Characterization of matriptase expression in normal human tissues. J Histochen Cytochem 51: 1017-1025, 2003.

41. Oberst MD, Johnson MD, Dickson RB, Lin CY, Singh B, Stewart M, Williams A, al Nafussi A, Smyth JF, Gabra H and Sellar GC: Expression of the serine protease matriptase and its inhibitor HAI-1 in epithelial ovarian cancer: correlation with clinical outcome and tumor clinicopathological parameters. Clin Cancer Res 8: 1101-1107, 2002.

42. Lin CY, Tseng IC, Chou FP, Su SF, Chen YW, Johnson MD and Dickson RB: Zymogen activation, inhibition, and ectodomain shedding of matriptase. Front Biosci 13: 621-635, 2008.

43. Benaud CM, Oberst M, Dickson RB and Lin CY: Deregulated activation of matriptase in breast cancer cells. Clin Exp Metastasis 19: 639-649, 2002.

44. Cantero D, Friess H, Deflorin J, Zimmermann A, Brundler MA, Riesle E, Korc M and Buchler MW: Enhanced expression of urokinase plasminogen activator and its receptor in pancreatic carcinoma. Br J Cancer 75: 388-395, 1997.

45. Bauer TW, Liu W, Fan F, Camp ER, Yang A, Somcio RJ, Bucana CD, Callahan J, Parry GC, Evans DB, Boyd DD, Mazar AP and Ellis LM: Targeting of urokinase plasminogen activator receptor in human pancreatic carcinoma cells inhibits c-Met- and insulin-like growth factor-I receptor-mediated migration and invasion and orthotopic tumor growth in mice. Cancer Res 65: 7775-7781, 2005.

46. Maehara N, Matsumoto K, Kuba K, Mizumoto K, Tanaka M and Nakamura T: NK4, a four-kringle antagonist of HGF, inhibits spreading and invasion of human pancreatic cancer cells. Br J Cancer 84: 864-873, 2001

47. Christensen JG, Schreck R, Burrows J, Kuruganti P, Chan E, Le P, Chen J, Wang X, Ruslim L, Blake R, Lipson KE, Ramphal J, Do S, Cui JJ, Cherrington JM and Mendel DB: A selective small molecule inhibitor of c-Met kinase inhibits c-Met-dependent phenotypes in vitro and exhibits cytoreductive antitumor activity in vivo. Cancer Res 63: 7345-7355, 2003.

48. Overall CM and Dean RA: Degradomics: systems biology of the protease web. Pleiotropic roles of MMPs in cancer. Cancer Metastasis Rev 25: 69-75, 2006

49. Matsumoto $\mathrm{K}$ and Nakamura T: NK4 gene therapy targeting HGF-Met and angiogenesis. Front Biosci 13: 1943-1951, 2008.

50. Saimura M, Nagai E, Mizumoto K, Maehara N, Okino H, Katano M, Matsumoto K, Nakamura T, Narumi K, Nukiwa T and Tanaka M: Intraperitoneal injection of adenovirus-mediated NK4 gene suppresses peritoneal dissemination of pancreatic cancer cell line AsPC-1 in nude mice. Cancer Gene Ther 9: 799-806, 2002.

51. Ramsay AJ, Reid JC, Velasco G, Quigley JP and Hooper JD: The type II transmembrane serine protease matriptase-2-identification, structural features, enzymology, expression pattern and potential roles. Front Biosci 13: 569-579, 2008. 